\title{
Single-mode pumped high air-fill fraction photonic crystal fiber taper for high-power deep-blue supercontinuum sources
}

Sørensen, Simon Toft; Larsen, Casper; Jakobsen, Christian; Thomsen, Carsten L.; Bang, Ole

Published in:

Optics Letters

Link to article, DOI:

10.1364/OL.39.001097

Publication date:

2014

Document Version

Publisher's PDF, also known as Version of record

Link back to DTU Orbit

Citation (APA):

Sørensen, S. T., Larsen, C., Jakobsen, C., Thomsen, C. L., \& Bang, O. (2014). Single-mode pumped high air-fill fraction photonic crystal fiber taper for high-power deep-blue supercontinuum sources. Optics Letters, 39(4), 1097-1100. https://doi.org/10.1364/OL.39.001097

\section{General rights}

Copyright and moral rights for the publications made accessible in the public portal are retained by the authors and/or other copyright owners and it is a condition of accessing publications that users recognise and abide by the legal requirements associated with these rights.

- Users may download and print one copy of any publication from the public portal for the purpose of private study or research.

- You may not further distribute the material or use it for any profit-making activity or commercial gain

- You may freely distribute the URL identifying the publication in the public portal 


\title{
Single-mode pumped high air-fill fraction photonic crystal fiber taper for high-power deep-blue supercontinuum sources
}

\author{
Simon T. Sørensen, ${ }^{1,2}$ Casper Larsen, ${ }^{1}$ Christian Jakobsen, ${ }^{2}$ Carsten L. Thomsen, ${ }^{2}$ and Ole Bang ${ }^{1,2, *}$ \\ ${ }^{1}$ DTU Fotonik, Department of Photonics Engineering, Technical University of Denmark, 2800 Kgs. Lyngby, Denmark \\ ${ }^{2}$ NKT Photonics A/S, Blokken 84, DK-3460, Birkerød, Denmark \\ ${ }^{*}$ Corresponding author: oban@fotonik.dtu.dk
}

Received November 29, 2013; revised January 15, 2014; accepted January 15, 2014; posted January 22, 2014 (Doc. ID 202307); published February 14, 2014

\begin{abstract}
Dispersion control with axially nonuniform photonic crystal fibers (PCFs) permits supercontinuum (SC) generation into the deep-blue from an ytterbium pump laser. In this Letter, we exploit the full degrees of freedom afforded by PCFs to fabricate a fiber with longitudinally increasing air-fill fraction and decreasing diameter directly on the draw-tower. We demonstrate SC generation extending down to $375 \mathrm{~nm}$ in one such monolithic fiber device that is single-mode at $1064 \mathrm{~nm}$ at the input end. (c) 2014 Optical Society of America

OCIS codes: (060.4370) Nonlinear optics, fibers; (060.5295) Photonic crystal fibers; (320.6629) Supercontinuum generation.

http://dx.doi.org/10.1364/OL.39.001097
\end{abstract}

The formation of extremely broad supercontinuum (SC) spectra in highly nonlinear optical fibers has been extensively studied, driven both by an interest in understanding the underlying physics and due to a large commercial potential [1]. A considerable ongoing effort has been devoted to extend the $\mathrm{SC}$ into the infrared in nonsilica glasses [2-5] and into the deep-blue in tapered silica photonic crystal fibers (PCFs) [ $\underline{6}-11]$. Specifically, the deep-blue spectral region below $400 \mathrm{~nm}$ is highly desirable for biological applications such as fluorescent microscopy [6], but accessing this region with typical commercial SC sources based on long-pulsed ytterbium fiber-lasers with tens of kilowatt of peak power is only possible with high air-fill fraction PCFs. This makes the fibers (highly) multimode at the pump, complicates coupling, and limits the applicability. In such sources, the spectral broadening is initiated by noise-driven modulation instability (MI) that breaks the pump pulse into a distributed spectrum of solitons and dispersive waves (DWs) [12]. The SC spectrum is subsequently shaped by a complex process in which the Raman redshifting solitons trap the cohort of DWs, thereby forcing them to blueshift so as to propagate with the group velocity (GV) of the redshifting solitons $[13,14]$. Ultimately, the spectral width is determined, on the long wavelength "red" side, by the maximum extent of the soliton redshift and, on the short wavelength "blue" side, by the GV matching to the solitons. The soliton redshift typically is limited by the increasing material loss at $\sim 2.3 \mu \mathrm{m}$ and the blue SC edge can then be predicted by the GV match from this wavelength $[7,9]$.

Tapering of $\mathrm{PCFs}$ with high air-fill fractions has proven an effective way of extending the spectra into the deepblue by shaping the GV landscape [ $\underline{6}-11]$. This facilitates the ideal combination of (1) an initial fiber section to initiate the spectral broadening by MI in the vicinity of the zero-dispersion wavelength (ZDW) with an efficient energy transfer into the visible, and (2) a subsequent fiber section with GV matching to gradually shorter wavelengths. Previous reports on blue-extended SC generation typically relied on tapered PCFs where the air hole structure is preserved [ $\underline{6}-11]$, i.e., with constant hole-to-pitch ratio $(d / \Lambda)$ and decreasing hole-to-hole pitch $(\Lambda)$. However, high air-fill fraction PCFs are inevitably multimode at the pump, which in combination with the large air holes can greatly complicate coupling and interfacing. Moreover, light from higher-order modes adds to the noise and decreases the resolution in several applications. In $[\underline{15}, \underline{16}]$ this was overcome by increasing the air hole size in a short section of an endlessly singlemode PCF using a post processing technique, but only to enhance the visible power. Air-fill fraction varying PCFs were used for pulse compression in $[17,18]$, where the air hole size was controlled by adjusting the pressure on the air holes during the fiber draw. However, the resulting change in air-fill fraction was relatively small in both cases. In this Letter, we present the first high-power SC generation into the deep-blue in a single-mode PCF with longitudinally increasing air-fill fraction of more than $60 \%$ and decreasing pitch fabricated directly at the drawtower. The large increase in the air-fill fraction uniquely ensures single-mode behavior at $1064 \mathrm{~nm}$ at the input and GV matching into the deep-blue at the output.

To motivate our fiber design, we show in Fig. 1 the calculated dispersion and GV at equidistant points along the length of a PCF, in which the hole-to-pitch ratio is linearly increased from 0.52 to 0.85 while the pitch is linearly decreased from 3.3 to $2.0 \mu \mathrm{m}$. The final structure with a hole-to-pitch ratio of 0.85 and a pitch of $2.0 \mu \mathrm{m}$ is our target design, for which GV matching to the loss edge of $2.3 \mu \mathrm{m}$ gives a theoretical blue edge of $360 \mathrm{~nm}$, the shortest possible for a hole-to-pitch ratio of $0.85[7,9]$. We emphasize that the long wavelength spectral edge of $2.3 \mu \mathrm{m}$ is an estimate typical of the pump and PCF used in this Letter (see, e.g., nktphotonics.com), but that the GV matching is relatively unaffected by the exact position [9]. Figure 1 shows that the ZDW shifts from $1033 \mathrm{~nm}$ at the input to gradually shorter wavelengths. The GV decreases at long wavelengths where waveguide dispersion dominates over material dispersion, which gives GV 

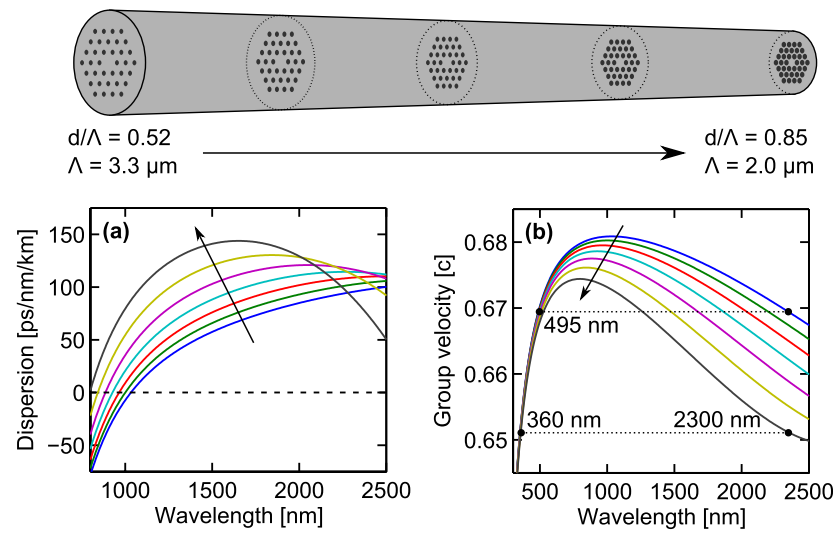

Fig. 1. Calculated (a) dispersion and (b) GV for the illustrated hole-size increasing PCF taper. The hole-to-pitch ratio $d / \Lambda$ and pitch $\Lambda$ are assumed to vary linearly with length, and the dispersion and GV are calculated at equidistant points.

matching to gradually shorter wavelengths from these long wavelengths. It should be noted that a continually decreasing GV is essential for the trapping process, although a too rapid decrease can be detrimental due to group-acceleration mismatch (GAM) $[\underline{8}, \underline{9}, \underline{14}, \underline{19}]$. Importantly, the trends in Fig. 1 are exactly as for tapered PCFs with a constant hole-to-pitch ratio and the conclusions from, e.g., $[\underline{7}-\underline{9}, \underline{19}]$ are therefore directly applicable here. We chose the particular fiber parameters in Fig. 1 to give the optimum conditions in both ends of the fiber: at the input end, the low air-fill fraction, and large core makes the PCF single-mode at $1064 \mathrm{~nm}$ [20] and gives a ZDW near the pump, while at the output end, the high air-fill fraction and small core ensures GV matching from the loss edge at $2.3 \mu \mathrm{m}$ into the deep-blue at $360 \mathrm{~nm}$. This is more than $100 \mathrm{~nm}$ shorter than what can be achieved in a PCF with the hole-to-pitch ratio and pitch of the input end, as illustrated in Fig. 1(b).

We would like to emphasize that the fiber is only single-mode at the pump wavelength at the input end [20], but that coupling from the fundamental to higherorder modes generally is negligible due to a large wavevector mismatch and small spatial mode overlap [21]. It is therefore important that the fiber is single-mode at the input, so that no higher-order modes are excited.

PCFs can be tapered with high accuracy during the fiber draw by controlling the draw speed [9-11]. However, increasing the air-fill fraction necessitates an additional control of the pressure on the air holes during fabrication. To realize the targeted design of Fig. 1, we therefore rapidly increased the pressure during the draw, so that the hole-to-pitch ratio increases to a new equilibrium value determined by the increased pressure. This is illustrated in Fig. 2(a), where the hole-to-pitch ratio and pitch determined from microscope images are shown at equidistant points in the fiber. The hole-to-pitch ratio increases linearly to the desired value of 0.85 after approximately $8 \mathrm{~m}$. This, however, also leads to an undesirable increase in the pitch. The pitch can be controlled by the draw speed (through mass conservation), and by simultaneously increasing the pressure and draw speed, it is hence possible to draw a PCF with increasing holeto-pitch ratio and decreasing pitch. From a number of (a) Pressure control only

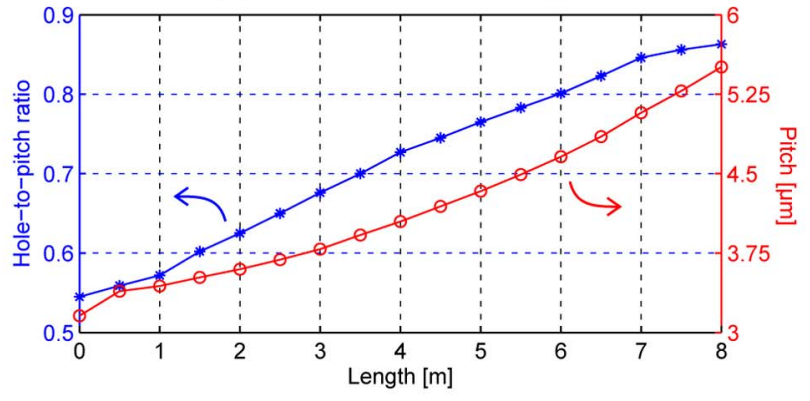

(b) Pressure and draw speed control

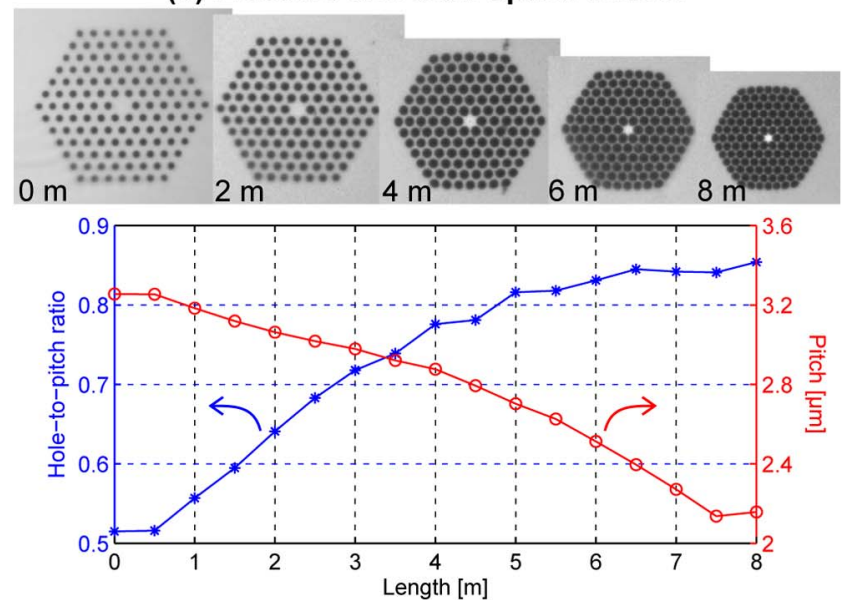

Fig. 2. Characterization of the fiber structure for air-fill fraction increasing PCFs drawn by (a) increasing the pressure on the air holes and (b) additionally increasing the draw speed. The fiber parameters are determined from microscope images of the fiber end facet at selected distances from the input as shown in (b).

iterative fiber draws we found that the draw speed had to be increased by more than a factor of seven simultaneously with the pressure increase to give the desired pitch at the output. The realized fiber structure is shown in Fig. 2(b): the hole-to-pitch ratio increases from 0.52 to 0.85 over $7 \mathrm{~m}$, while the pitch decreases from 3.3 to $2.15 \mu \mathrm{m}$. This is very close to the targeted hole-to-pitch ratio of 0.85 and pitch of $2.0 \mu \mathrm{m}$, albeit a slightly too large pitch. This large increase in the hole-to-pitch ratio over a length of several meters has never been demonstrated before. In comparison, the hole-to-pitch ratio was decreased from 0.52 to 0.42 in [18]. It should be noted that the preform used in this work has a "natural" hole-topitch ratio of $d / \Lambda=0.52$ and that large deviations from this value will cause perturbations of the air-silica matrix. We shall return to this point later. However, the microscope images in Fig. 2(b) show that the hexagonal structure is reasonably well preserved during the air hole expansion, which highlights the amazing design freedom in PCFs and clearly verifies the feasibility of our design.

To investigate the PCF's applicability for SC generation, we pumped the fiber with a $1064 \mathrm{~nm} \mathrm{Yb}$ fiber-laser typical of many SC experiments emitting 10 ps pulses at $15 \mathrm{~W}$ average power and $80 \mathrm{MHz}$ repetition rate. The $\mathrm{PCF}$ was spliced directly to the fiber-laser using a filament splicer, resulting in a coupling loss of approximately $1.2 \mathrm{~dB}$. We kept an initial $40 \mathrm{~cm}$ length of uniform fiber 


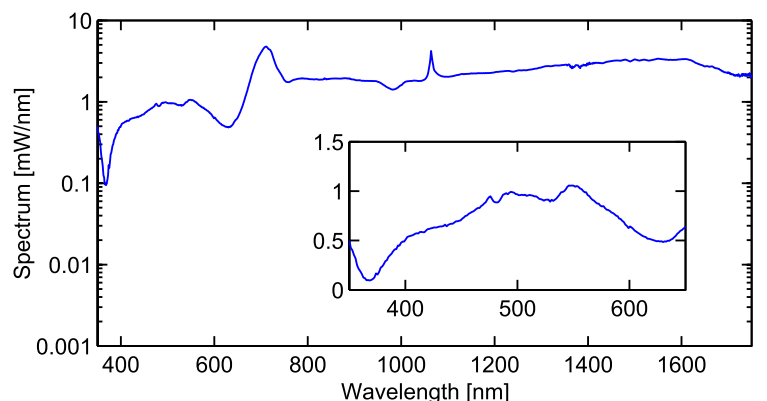

Fig. 3. Measured SC spectrum. The inset shows a close-up of the spectral blue edge on a linear scale. The total output power was $5.8 \mathrm{~W}$ with $734 \mathrm{~mW}$ in the visible part of the spectrum below $900 \mathrm{~nm}$

to initiate the spectral broadening. The generated spectrum recorded with an optical spectrum analyzer and an integrating sphere is shown in Fig. 3. The SC spectrum indeed extends into the deep-blue with a spectral density above $0.5 \mathrm{~mW} / \mathrm{nm}$ in most of the visible bandwidth. The spectrum had a total power of $5.8 \mathrm{~W}$ with $734 \mathrm{~mW}$ in the visible part below $900 \mathrm{~nm}$ and extends down to $375 \mathrm{~nm}$, the spectral intensity measured below this wavelength is due to stray light. The far-field image of the fiber output showed no sign of light from any higher-order modes.

The discrepancy between the measured spectral blue edge at $375 \mathrm{~nm}$ and the theoretical target at $360 \mathrm{~nm}$ can be understood by investigating the fiber structure in more detail. A closer inspection of the fiber structure at the output end reveals that the innermost air holes are elongated due to the extreme air hole expansion (see insets in Fig. 4). An ideal hexagonal PCF with a 0.85 hole-to-pitch ratio and $2.0 \mu \mathrm{m}$ pitch has a core diameter of approximately $\Lambda(2-d / \Lambda) \approx 2.3 \mu \mathrm{m}$, whereas the core diameter of our PCF is approximately $1.8 \mu \mathrm{m}$ measured from the microscope images. This core size corresponds to an effective pitch of $1.6 \mu \mathrm{m}$. To verify this approximation, we show in Fig. 4 the measured dispersion (thick lines) at the input and output end of the fiber together with the calculated dispersion (thin lines) for the input $(d / \Lambda=0.52, \Lambda=3.3 \mu \mathrm{m})$, ideal $(d / \Lambda=0.85, \Lambda=2.0 \mu \mathrm{m})$, and effective $(d / \Lambda=0.85$, $\Lambda=1.6 \mu \mathrm{m})$ output parameters. The dispersion was measured in $8 \mathrm{~cm}$ lengths of fiber with a low coherence

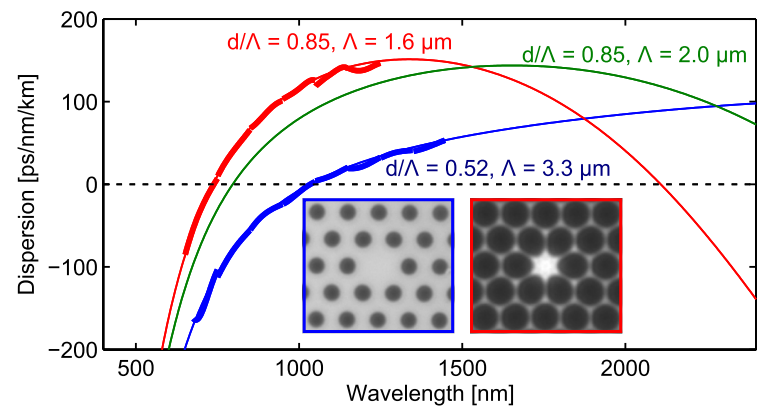

Fig. 4. Measured dispersion (thick lines) at the input and output of the PCF in Fig. 2, and corresponding calculated dispersion (thin lines) for P $\bar{C} F s$ with the values of the holeto-pitch ratio $d / \Lambda$ and pitch $\Lambda$ stated in the plot. The insets show a close-up of the fiber structure around the core at the input (left) and output (right) end.
Mach-Zehnder interferometer in the frequency domain [22] and is shown in individually measured $100 \mathrm{~nm}$ bandwidths. The results in Fig. 4 show an excellent agreement between experiment and theory at the input and output, which verifies that the output end is well described by an effective pitch of $1.6 \mu \mathrm{m}$. Moreover, this effective pitch gives a theoretical GV matched blue edge of $370 \mathrm{~nm}$ (assuming the soliton redshift halts $50 \mathrm{~nm}$ from the second ZDW) in fair agreement with the measured spectrum. It should be noted that our setup only allowed us to measure the dispersion in the visible and near-infrared, and the GV matching is therefore found from the theoretical calculations.

We emphasize that the fiber parameters in Fig. 1 are calculated over the entire PCF structure. The structure only deviates from an ideal hexagonal structure in the innermost air holes for hole-to-pitch ratios larger than $\sim 0.75$, which is far from the preform's natural hole-topitch ratio of 0.52 and due to the extreme air hole expansion that perturbs the air-silica matrix. Currently, we are limited by the accuracy and control of the air hole inflation. The tapering process is more straightforward and highly reproducible, as shown in [10]. The next optimization step is to use a preform with a higher hole-topitch ratio to lessen the deformation of the innermost air holes. Despite these current shortcomings, our results clearly demonstrate the applicability of air-fill fraction increasing PCFs for single-mode pumped deep-blue SC generation.

To conclude, we fabricated the first single-mode high air-fill fraction PCF directly on the draw-tower with a record increase in air-fill fraction of more than $60 \%$ and demonstrated SC generation extending down to $375 \mathrm{~nm}$ from a $1064 \mathrm{~nm}$ pump. The PCF was designed with increasing hole-to-pitch ratio and decreasing pitch, which permits single-mode operation at the pump wavelength at the input and a GV match into the deep-blue at the output. This unique combination makes our air-fill fraction increasing PCF a promising candidate for high-power deep-blue SC sources.

We would like to thank J. K. Lyngsø for help with the dispersion measurements and the Danish Agency for Science, Technology and Innovation for support of project no. 09-070566.

\section{References}

1. J. M. Dudley, G. Genty, and S. Coen, Rev. Mod. Phys. 78, 1135 (2006).

2. C. Xia, M. Kumar, O. P. Kulkarni, M. N. Islam, F. L. Terry, M. J. Freeman, M. Poulain, and G. Mazé, Opt. Lett. 31, 2553 (2006).

3. G. Qin, X. Yan, C. Kito, M. Liao, C. Chaudhari, T. Suzuki, and Y. Ohishi, Appl. Phys. Lett. 95, 161103 (2009).

4. C. Agger, C. Petersen, S. Dupont, H. Steffensen, J. K. Lyngs $\varnothing$, C. L. Thomsen, J. Thøgersen, S. R. Keiding, and O. Bang, J. Opt. Soc. Am. B 29, 635 (2012).

5. C. L. Thomsen, F. D. Nielsen, J. Johansen, P. M. Moselund, U. Møller, S. T. Sørensen, C. Larsen, and O. Bang, Proc. SPIE 8637, 86370T (2013).

6. A. Kudlinski, M. Lelek, B. Barviau, L. Audry, and A. Mussot, Opt. Express 18, 16640 (2010).

7. J. C. Travers, J. Opt. 12, 113001 (2010).

8. S. T. Sørensen, A. Judge, C. L. Thomsen, and O. Bang, Opt. Lett. 36, 816 (2011). 
9. S. T. Sørensen, U. Møller, C. Larsen, P. M. Moselund, C. Jakobsen, J. Johansen, T. V. Andersen, C. L. Thomsen, and O. Bang, Opt. Express 20, 10635 (2012).

10. U. Møller, S. T. Sørensen, C. Larsen, P. M. Moselund, C. Jakobsen, J. Johansen, C. L. Thomsen, and O. Bang, Opt. Fiber Technol. 18, 304 (2012).

11. J. Stone and J. Knight, Opt. Fiber Technol. 18, 315 (2012).

12. M. Islam, G. Sucha, and I. Bar-Joseph, J. Opt. Soc. Am. B 6, 1149 (1989).

13. P. Beaud, W. Hodel, B. Zysset, and H. P. Weber, IEEE J. Quantum Electron. QE-23, 1938 (1987).

14. A. V. Gorbach and D. V. Skryabin, Nat. Photonics 1, 653 (2007).
15. W. Wadsworth, A. Witkowska, S. Leon-Saval, and T. Birks, Opt. Express 13, 6541 (2005).

16. C. Xiong, A. Witkowska, S. G. Leon-Saval, T. A. Birks, and W. J. Wadsworth, Opt. Express 14, 6188 (2006).

17. M. L. V. Tse, P. Horak, J. H. V. Price, F. Poletti, F. He, and D. J. Richardson, Opt. Lett. 31, 3504 (2006).

18. J. C. Travers, J. M. Stone, A. B. Rulkov, B. A. Cumberland, A. K. George, S. V. Popov, J. C. Knight, and J. R. Taylor, Opt. Express 15, 13203 (2007).

19. J. C. Travers and J. R. Taylor, Opt. Lett. 34, 115 (2009).

20. M. Koshiba and K. Saitoh, Opt. Lett. 29, 1739 (2004).

21. J. K. Ranka, R. S. Windeler, and A. J. Stentz, Opt. Lett. 25, 796 (2000).

22. J. Y. Lee and D. Y. Kim, Opt. Express 14, 11608 (2006). 